OPEN ACCESS

Edited by:

Rabi Mohtar,

Texas A\&M University, United States

Reviewed by:

Nidhi Nagabhatla, United Nations University Institute for

Water Environment and Health,

Canada

Marloes L. Mul,

IHE Delft Institute for Water

Education, Netherlands

*Correspondence:

Holger Hoff

hhoff@pik-potsdam.de

Specialty section:

This article was submitted to

Freshwater Science,

a section of the journal

Frontiers in Environmental Science

Received: 07 November 2018 Accepted: 28 March 2019

Published: 24 April 2019

Citation:

Hoff H, Alrahaife SA, El Hajj R, Lohr K, Mengoub FE, Farajalla N, Fritzsche $K$, Jobbins G, Özerol G, Schultz $R$ and Ulrich A (2019) A Nexus Approach for the MENA Region-From Concept to

Knowledge to Action

Front. Environ. Sci. 7:48.

doi: 10.3389/fenvs.2019.00048

\section{A Nexus Approach for the MENA Region-From Concept to Knowledge to Action}

\author{
Holger Hoff ${ }^{1,2 *}$, Sajed Aqel Alrahaife ${ }^{3}$, Rana El Hajj ${ }^{4}$, Kerstin Lohr ${ }^{5}$, \\ Fatima Ezzahra Mengoub ${ }^{6}$, Nadim Farajalla ${ }^{4}$, Kerstin Fritzsche ${ }^{7}$, Guy Jobbins ${ }^{8}$, \\ Gül Özerol ${ }^{9}$, Robert Schultz $^{5}$ and Anne Ulrich ${ }^{10}$
}

${ }^{1}$ Potsdam Institute for Climate Impact Research, Potsdam, Germany, ${ }^{2}$ Stockholm Environment Institute, Stockholm, Sweden, ${ }^{3}$ Greater Karak Municipality, Karak, Jordan, ${ }^{4}$ Issam Fares Institute for Public Policy and International Affairs, American University of Beirut, Beirut, Lebanon, ${ }^{5}$ GlZ, Global Project "Sustainable Energy for Food-Powering Agriculture, "Bonn, Germany, ${ }^{6}$ Policy Center for the New South, Rabat, Morocco, ${ }^{7}$ Institute for Advanced Sustainability Studies, Potsdam, Germany, ${ }^{8}$ Overseas Development Institute, London, United Kingdom, ${ }^{9}$ Department of Governance and Technology for Sustainability, University of Twente, Enschede, Netherlands, ${ }^{10}$ Forest Research Institute Baden-Wuerttemberg, Freiburg, Germany

There is wide agreement that a nexus or integrated approach to managing and governing natural resources such as land, water, and energy can improve environmental, climate, human, and political security. However, few if any countries in the MENA region have made progress in implementing such an approach. There appear to be several constraints inhibiting the development and adoption of nexus approaches. These constraints include strong sectoral silos, insufficient incentives for integrated planning and policy making at all levels, and limited vision, knowledge, and practical experience to guide successful implementation. In turn, the limited implementation and hence lack of empirical evidence of a nexus approach, which could demonstrate its benefits, does little to strengthen political will for the development of adequate incentives, structures, and procedures. Against this backdrop, this paper presents five case studies which take an integrated approach, in three MENA countries, namely Jordan, Lebanon, and Morocco. Based on an analytical framework developed here, the paper analyses and compares the success factors for nexus implementation, and also for transfer and upscaling. The analysis emphasizes the need for appropriate framework conditions, targeted investments and pioneering actors, to make integrated approaches across sectors and levels work. With the evidence presented, the paper aims to set in motion a positive or virtuous cycle of generating more nexus evidence, improved framework conditions, further nexus implementation on the ground, and from that even more nexus evidence. Finally, the paper contributes to overcoming the repeated requests for better definition and conceptualization of the nexus, which often has slowed down adoption of the concept.

Keywords: nexus, tradeoffs, synergies, integrated management, policy coherence, MENA region 


\section{INTRODUCTION}

The Middle East and North Africa (MENA) region is characterized by extreme water as well as land scarcity, low (cross-) resource use efficiencies despite growing urgency (Sullivan, 2013; Waterbury, 2017) and increasing human insecurities-being the only region in the world with decreasing food security (FAO, 2015). Agricultural production could decrease in future $(\mathrm{OECD} / \mathrm{FAO}, 2018)$. These trends converge with a rapid transition toward renewable energy as well as toward non-conventional water, with uncertain cross-resource and cross-sector impacts. However, weak governance and large implementation gaps exist in all the sectors, aggravated by a lack of policy coherence, which however is not specific to the MENA region.

This situation begs for the integrated management of natural resources such as water, energy, land and biomass, and integrated governance across sectors. Such integrated approaches will strengthen human, as well as water, energy and food security, environmental and climate security and eventually also political security. This is what the socalled nexus approach ${ }^{1}$ promises (Hoff, 2011; Allan et al., 2015; Al-Saidi and Elagib, 2017). However, there is very limited progress so far in the operationalization of the nexus concept in policy making and its implementation on the ground (Leck et al., 2015). This implementation challenge is particularly critical in the MENA region, where several constraints contribute to this dilemma, such as insufficient incentives, limited vision, knowledge, and experience to guide technology development and investment, and in particular the absence of concrete examples and applied practices (Mansour et al., 2017; Weitz et al., 2017a).

The lack of practical nexus implementation implies that there is little empirical evidence of the potential benefits and added value of applying the nexus approach as well as of the challenges associated with it. This lack of evidence in turn limits political will for the development of adequate framework conditions, structures, and funding that would support nexus implementation. In order to break this vicious cycle and turn it into a virtuous cycle, examples of good practice of nexus implementations on the ground and accompanying quantitative analyses are required (Al-Saidi and Elagib, 2017). Such analyses can demonstrate the benefits of integrated approaches and practices. The empirical evidence from such analyses could help to overcome inertia, vested, and short-term interests, path dependencies, and other disincentives to reform and encourage nexus thinking and action. At the same time, such practical evidence can address the cross-sector interdependencies and challenges when implementing the Sustainable Development Goals (SDGs) (Weitz et al., 2014a; Leck et al., 2015; Rasul, 2016), and climate adaptation and mitigation goals of the Nationally Determined Contributions (NDCs) (Rasul and Sharma, 2015; Brandi et al., 2017; Pardoe et al., 2017).

\footnotetext{
${ }^{1}$ Nexus is the Latin word for interlinkages, a nexus approach assesses interlinkages (synergies and tradeoffs) across sectors and resources, and - based on that evidence - promotes integrated management and governance, see Hoff (2011).
}

Against this backdrop, our paper presents a set of cases in the MENA region, which were selected for their integrated approaches, involving several sectors and natural resources. These cases provide an initial evidence base for a comparative analysis from a nexus perspective. Our paper aims at identifying success factors for future nexus projects, synthesizing lessons learned, including challenges, and a general way forward in making the nexus work. In order to do so, the paper develops and applies an analytical framework for evaluating and comparing the different cases, drawing on existing literature. The paper is structured as follows:

- The second section provides a review of the current state of the literature in the conceptualization and practical implementation of the nexus, highlighting in particular unresolved issues and criticisms to the nexus approach.

- Taking the findings from the literature review into consideration, section Analytical Framework develops an analytical framework for the analysis and comparison of the different cases, which are involving different sectors and natural resources.

- Subsequently, in section Case studies and selected crosssectoral approaches the analytical framework is applied to five selected cases in Morocco, Jordan and Lebanon, assessing the associated benefits and added value as well as costs of applying an integrated approach.

- Section Comparative analysis across case studies and lessons learned summarizes key findings from the analysis of the five cases, highlighting in particular good practices, lessonslearned, required framework conditions, opportunities for transfer and upscaling as well as remaining challenges to the operationalization and implementation and of the nexus.

- Drawing on this discussion, the final section Conclusion synthesizes options for overcoming barriers and promoting nexus approaches in management and governance and mainstreaming the nexus across various MENA contexts.

\section{LITERATURE REVIEW}

Since its emergence and in particular following the Bonn Nexus Conference in 2011, the concept of the water-energy-food nexus (WEF nexus) ${ }^{2}$ has received wide attention in academic literature (e.g., Bazilian et al., 2011; Mohtar and Daher, 2012; Leck et al., 2015; Liu et al., 2017; Albrecht et al., 2018). It essentially underlines the need for integrated approaches to deal with complex issues at the intersection of natural and human systems. Or as Hoff (2011) puts it: "Conventional policy- and decision-making in "silos" (...) needs to give way to an approach that reduces trade-offs and builds synergies across sectorsa nexus approach." Already in the 1970s, academic literature on governance of complexity explored how policies could be designed to find integrated solutions to complex problems.

\footnotetext{
${ }^{2}$ While the water-energy-food nexus is one of the most frequently explored nexus constellations, it should be noted, that a nexus approach can also integrate other sectors (see an overview of different types of nexus in Endo et al., 2017). In the following, the paper will therefore more general refer to the "nexus" without further specification of the topics it relates to.
} 
Scharpf (1972) identified three major pitfalls that hinder policy making for complex issues: (1) segmented problem perception by theme-centered institutions that focus on parts of a problem and therefore tend to overlook interlinkages or problems in the space between different theme-centered institutions; (2) shortsighted solutions that do not enfold the desired impact due to being based on segmented problem perception; (3) neglecting negative implications or tradeoffs in other areas, emphasizing the need for coordination, to limit adverse effects which can reduce the overall efficiency of a system. By embracing complexity rather than trying to over-reduce it, the nexus approach aims to avoid such major pitfalls.

Environmental policy integration (EPI) and integrated water resources management (IWRM) have preceded the nexus approach in addressing cross-sectoral policy challenges (GWP, 2000; özerol et al., 2012; Weitz et al., 2017a). EPI in particular sought the vertical integration (across levels within sectors) and horizontal integration (between sectors) of environmental issues and objectives into governance (Lafferty and Hovden, 2002). EPI differs from the nexus approach by mainstreaming a particular environmental issue into other sectors of policyand decision-making, however without basically challenging segmented, sector-focused approaches. Similarly, IWRM strives for a more holistic and systemic understanding of a problem, but it still puts water into the center (GWP, 2000; Leck et al., 2015). The nexus approach, by contrast, applies a "multi-centric" (Liu et al., 2017) perspective that not only aims to transcend sectoral boundaries, but also to treat these different perspectives and stakeholders more or less equal in its considerations (White et al., 2017), trying to account for political economies and power differences between sectors when negotiating tradeoffs (Scott, 2017). As Hagemann and Kirschke (2017) point out, there are many similarities between the EPI and the nexus approach, such as the focus on interdependencies and trade-offs between different sectors, the consideration of different scales for problem solving (Hoff, 2018), or the emphasis of participation in management and governance.

Despite distinct features such as the focus on interlinkages, trade-offs and synergies between sectors and the multicentered perspective, there is no single approach to defining or operationalizing the nexus. Systematically reviewing 245 journal articles and book chapters, Albrecht et al. (2018) found a wide range of approaches, methods and purposes of a nexus approach, ranging from environmental management and economics, to energy and food system modeling and social sciences. The analysis further revealed that nexus studies are still often confined to disciplinary silos and fail to capture the full set of interlinkages between water, energy, and food (ibid.). Endo et al. (2017) also observe that there is no "fixed concept of nexus, and the nexus is internationally interpreted as a process to link ideas and actions of different stakeholders under different sectors and levels for achieving sustainable development." Weitz et al. (2017a) identify three gaps in the nexus literature that are currently only poorly addressed, namely the conditions for cross-sector coordination and collaboration, the dynamics beyond cross-sector interactions and political and cognitive factors as determinants of change. They describe the nexus approach as "conceptually inconclusive" and highlight the need for clarity on overarching objectives and guiding principles. In this vein, Jobbins et al. (2015) come to the conclusion that nexus approaches are not per se pro-poor and ask: is "the reduction of trade-offs between water, energy and food security considered an end in itself, or does it support higher-level social goals such as the reduction of poverty?" For this paper we argue that the nexus can help to achieve better social and economic outcomes while reducing pressure on natural resources and the environment-so called "decoupling," e.g., through enhancing resource use efficiencies across resources, through integrated management and governance and policy coherence.

Building on these critical reflections of the nexus concept, we argue that the current nexus literature lacks convincing case studies of cross-sector coordination and concrete implementation of nexus approaches, which would enable an analysis of challenges and opportunities and relevant framework conditions and. This holds particularly true for the MENA region with its urgent need for more integrated management and governance across sectors. This paper therefore aims to address this gap by providing a comparative analysis of five case studies in the MENA region, each of which involves several sectors. By showcasing these concrete examples, we also aim to provide evidence of the value that a nexus approach can add to policy and decision making. The following section describes our framework for the comparative analysis.

\section{ANALYTICAL FRAMEWORK}

In line with the mainstream of nexus literature (see chapter Literatur Review), we understand the nexus as a cross-sectoral and multi-level approach to deal with complex sustainability challenges. Rather than providing a set of clear guidelines or measures to apply, the nexus provides an approach that aims at creating a level playing field for all sectors while at the same time having sustainability (as defined in the SDGs) as an overarching aim. How this aim would be operationalized and met, however, is dependent on the specific case and the actors involved. Furthermore, embracing complexity in our view includes revealing and addressing political economies and asymmetries in power relations of involved actors and stakeholders and enabling them to better understand and address complex issues.

Starting from this understanding of the nexus approach, we develop a practice oriented analytical framework which enables a comparative analysis of the five case studies presented in this paper and guidance for future nexus implementation. The framework comprises six categories to be explored in detail for the description and analysis of the case studies:

1) Nexus framing: this category creates a common, contextspecific understanding of the key issues from a nexus perspective, explores the interlinkages between the different sectors and resources, and includes synergies and tradeoffs which could be relevant for the case study;

2) Nexus opportunities: this category identifies how a nexus approach could add value in the respective context, e.g., by 
improving (cross-)resource productivity, reducing resource and environmental degradation, increasing climate resilience, and reducing human insecurities/poverty/unemployment;

3) Technical and economic nexus solutions: this category assesses and if possible quantifies potential benefits from the implementation of nexus approaches or "nexus savings" in the respective case study, e.g., through multi-functional production systems, municipalities or landscapes, and crossresources and cross-sector recycling;

4) Stakeholders involved: this category specifies the different types and levels of stakeholders involved in the case study, e.g., from public and private sector and civil society, their respective roles, and what is required to make it successful;

5) Framework conditions: This category addresses relevant conditions and context factors including type (technical solutions, policy solutions, mix of measures) scale and level (e.g., farm-level, community-level, national level etc.) and the actual implementation of a nexus approach. It also aims to answer questions such as: how can the nexus approach be institutionalized, i.e., how can the experience from practical implementation be taken into account in policy and decision making, e.g., by improved cooperation between sectors and institutions? Have any new bridging mechanisms or even new nexus institutions been established yet, including integrated SDG and/or NDC implementation? Does this contribute to improving policy coherence and if so how? Do integrated approaches contribute to innovation (e.g., via entrepreneurs and incubators, also considering relevant framework conditions outside the nexus)?

6) Monitoring, evaluation and next steps: This category defines indicators and required data for monitoring and evaluation (M\&E) of the implementation of the nexus approach. It builds on the understanding that nexus implementation is a process with dynamic objectives, composition of stakeholders and processes and therefore requires a self-reflexive mechanism (institutional learning mechanism and multi-loop learning) to further evolve. This section also provides an outlook to the potential of each case study for replication and upscaling.

In the following sections, these six categories will be applied to evaluate and compare five selected case studies in the MENA region.

Note that our analytical framework goes beyond existing frameworks (e.g., Bizikova et al., 2013; Flammini et al., 2014; Mohtar and Daher, 2016) in that it synthesizes experience from existing case studies, each of which involves different sectors.

\section{CASE STUDIES AND SELECTED CROSS-SECTORAL APPROACHES}

Given the lack of explicit nexus approaches and implementations, which would have built into their design integrated management and governance across sectors, we analyze opportunistically five cases from Morocco, Jordan and Lebanon, each of which includes interlinkages across the water, energy and food/agriculture sectors. These cases or case studies start from different angles and objectives, cover different scales and contexts, and have different types of actors and stakeholders. Nevertheless, together they provide a rich set of new insights and valuable lessons for the design of future nexus projects and for integrated governance. The five cases included here start from: (i) drip irrigation (Morocco), (ii) solar water pumping for irrigation (Morocco), (iii) solar desalination and use of the desalinated water for biomass production (Jordan), (iv) integrated water, land and energy management at the municipal level (Jordan), and (v) integrated water, land and energy management at the farm level (Lebanon).

The case studies were opportunistically selected from ongoing cross-sectoral projects in the MENA region and indepth knowledge of each case by at least one co-author. The cases thus neither present full nexus implementations, nor are they fully representative for the region, however they give a valuable overview of integrated approaches on the ground. Before presenting the five case studies, we give a short introduction to the contexts of Morocco, Jordan and Lebanon, the countries in which the cases are embedded.

In Morocco, the agricultural sector, a major driving force for the national economy, consumes more than $80 \%$ of all water resources. The severe water scarcity is further exacerbated by the effects of climate change. Competition between different water uses is growing, besides agriculture also the water demands for industry, tourism, hydro-power (7\% of national energy production) and municipal drinking water continue to grow. Energy demand in agriculture (e.g., for water pumping) and in other sector is also rapidly increasing and still primarily met by fossil resources, for which Morocco is a net importer. Rationalization of water and energy use is crucial to develop the agricultural sector, improve farmers' incomes and ensure food security. We show here experience from two different sub-cases where drip irrigation was introduced and one case where solar energy for water pumping was introduced.

Jordan is one of the most water-scarce countries in the world and the situation is increasingly aggravated by population growth, by climate change and by the region's geopolitical situation. The country is heavily relying on (fossil) groundwater which is increasingly depleted. Agricultural production, which is an important source of livelihoods and employment in rural areas, is strongly limited by water scarcity and land and ecosystem degradation is a widespread phenomenon. Urban encroachment further reduces the availability of arable land. Irrigated and rainfed areas are projected to shrink by about $30 \%$ by 2050 compared to 2010 (Al-Bakri et al., 2013). Water quality is increasingly threatened by industrial and domestic discharge of untreated wastewater. Furthermore, the demand for energy has been growing rapidly and Jordan's energy sector is strongly import-dependent, resulting in high energy costs. Desalination for meeting drinking and irrigation water demands and for reducing the growing demand-supply gap is very energy intensive, and hence is competing with other energy demands. Moreover, desalination relies on the use of fossil fuels, causing increased greenhouse gas (GHG) emissions. Water transfers are also very energy intensive in Jordan due to large elevation differences over which water needs to be pumped.

In Lebanon overexploitation and mismanagement of water resources, water quality degradation as well as energy scarcity 
(near total dependence on imports of fossil fuels) and deficit government electricity supply, further aggravated by rapid and unorganized development and climate change impacts, present major challenges. Water and electricity infrastructure are poor. The country experiences continued loss of agricultural land to urban expansion or rural-urban migration. Inefficient agricultural practices and increasing cost of agricultural production (also due to higher costs for water and energy) contribute to a shrinking agricultural sector within the overall national economy. Meanwhile agricultural discharges degrade water resources, and water scarcity reduces the hydropower potential.

\section{Case Study 1: Drip Irrigation in Morocco; Sub-cases of Oum Rbiaa River in Tadla-Azilal, Bitit, and Ain Chegag in Sebou, Lamzoudia in Tensift, and Guerdane and Issen in Souss Massa Nexus Framing}

Adopting drip irrigation can increase the efficiency of water and energy use in agriculture (same amount of food production using less water and requiring less energy for pumping). Under certain conditions, this can reduce agriculture's overall consumption of water and energy. However, higher water and energy efficiencies from drip irrigation can incentivise farmers to intensify their production, expand irrigated areas and to adopt more water intensive crops ("rebound effect"). By minimizing excess application of water, drip irrigation also reduces return flows of water to aquifers that are available to other users. These effects mean that despite local savings, pressure on water resources at basin or national level can remain high or even increase. Moreover, it is not clear if all farmers benefit equally from the new technology and if inequities can be reduced.

\section{Nexus Opportunities}

Increasing water and energy efficiencies can improve agricultural productivity, gross margins and food security. In principle, additional co-benefits might be realized, but this depends on higher water and energy efficiencies resulting in reduced overall consumption. These co-benefits might include improved environmental flows, enhanced climate resilience, and climate mitigation, mitigation of water- (and energy-) related conflicts and other economy-wide nexus opportunities, e.g., re-allocation of water to other sectors including hydropower and drinking water. While in the Oum Rbiaa River case some of these benefits have been realized, these opportunities strongly depend on appropriate framework conditions in terms of legislation and regulation, otherwise there is a risk of negative outcomes as in the Bitit, Ain Chegag, Lamzoudia, Guerdane, and Issen cases.

\section{Technical and Economic Nexus Solutions}

Modernization of irrigation through introduction of pressurized drip irrigation can increase water and energy use efficiency. However, these technical nexus solutions need to be accompanied by effective policy, regulatory, and institutional measures, in order to reduce overall water and energy consumption.

\section{Stakeholders Involved}

Civil society-local farmers, private land owners and other stakeholders and NGOs. Public institutions-Morocco Agricultural Development Office (Office de Mise en Valeur Agricole), river basin agencies (responsible for water distribution among sectors), sources of public subsidies, policy makers in agriculture, and water. Institutions from different sectors (e.g., water, agriculture and energy) and different levels (e.g., national, regional and local) don't necessarily have consistent policy objectives and coordination between them takes time. Attempts to merge different ministries (e.g., water, energy, and environment) have not been very successful. Investors, including World Bank and African Development Bank. Private businesses, which pursue goals develop technical innovations.

\section{Framework Conditions}

The Government of Morocco, e.g., through the Plan Vert (for a modernized green and pro-poor agriculture) or the Programme National d'Economie d'Eau d'Irrigation encourages drip irrigation, with specific investments in irrigation schemes as well as general subsidies. Effective legislation, policies, institutions, and regulations are needed to ensure that increased efficiencies are translated into real water and energy savings rather than leading to overuse and rebound effects. These framework conditions also include the regulation of water abstractions, limiting the number of new wells, and reviewing and revising pricing systems and subsidies. In the absence of such measures, drip irrigation may well make existing problems worse. Knowledge transfer from existing implementations and technical assistance for farmers need to be broadened and intensified, e.g., through the Moroccan Agricultural Development Office and the Ministry of Agriculture, as well as "guichet unique" (one-stopshops) which treat farmers demands.

\section{Monitoring and Evaluation and Next Steps}

The effects of the implementation of new drip irrigation technologies need to be monitored and evaluated systemically (i.e., from a nexus perspective), the potential effects of upscaling e.g., on groundwater levels, need to be modeled and the results and lessons learned need to be communicated to farmers, decision and policy makers for improving implementation and framing it in adequate legislation, regulation, and enforcement (also addressing illegal abstractions). Such a dialogue will have to involve practitioners, policy makers and scientists from universities and think tanks. So far monitoring (by ORMVAs) is limited to local efficiency improvements and fee recovery from users.

\section{Case Study 2: Solar Powered Irrigation at the Farm Level in Marrakesh, Midelt, and TATA Zones in Morocco}

\section{Nexus Framing}

Irrigation is limited (besides water scarcity) by high energy demand and associated cost. Replacing of fossil fuel with solar energy for pumping irrigation water has the potential to reduce costs and national import dependency for fossil energy. However, as solar energy is abundant in the MENA region, the lack of 
cost for operating the pumps may cause overexploitation of groundwater, due to the perception that "pumping is for free."

\section{Nexus Opportunities}

Solar pumping provides energy- and climate-smart agricultural water supply and supports the shift of the energy system to renewables. With that it contributes to climate change mitigation and it can reduce the cost of irrigation and improve farmers' income.

\section{Technical and Economic Nexus Solutions}

Switching from fossil to solar energy driven irrigation systems, e.g., for fruit, olive, and date trees and other crops, increases productivity (because of the improved availability of energy) and reduces fossil energy input into the agricultural sector.

\section{Stakeholders Involved}

Solar powered irrigation aims at small, medium-size and largescale farmers, other stakeholders include cooperatives, economic interest group (groupement d'intérêt économique-GIE), Ministries of Agriculture, Energy and Finance, Credit Agricole (for subsidies scheme), and local and national water authorities (in charge of the Programme National d'Economie d'Eau d'Irrigation). Vocational training institutions and technology suppliers are also involved.

\section{Framework Conditions}

Morocco's "Plan Vert" (for a modernized green and pro-poor agriculture) prescribes a transition to a green economy, phasing out fossil fuel subsidies. A key element of this transition is solar irrigation, which is planned for 100,000 ha through a targeted subsidy scheme. These subsidies are foreseen to directly benefit farmers in plant production and indirectly benefit the whole society through improvement in food security and (ideally) water availability and lower GHG emissions. Solar powered irrigation contributes to a wide range of SDG targets as well as to mitigation and adaptation targets of the NDCs.

\section{Monitoring and Evaluation and Next Steps}

Loan schemes and subsidy schemes as well as water governance rules are currently being set up for renewables and solar irrigation, Subsidies and sustainable pumping rates have to be endorsed and enforced by the government e.g., via management contracts. Since there are national solar water pumping programs in other countries as well (e.g., Tunisia and Jordan), this case study not only serves as reference for implementations in other parts of Morocco but also beyond.

\section{Case Study 3: Sahara Forest Project in Aqaba, Jordan \\ Nexus Framing}

Shifting to renewable (in particular solar) energy reduces dependency on fossil fuel imports and greenhouse gas emissions, which is crucial for mitigating climate change. Employing the renewable energy for desalination of seawater and for cooling of greenhouses in integrated production systems can enhance water availability, increase crop productivity and generate co-products and co-benefits (e.g., algae, fish, dryland restoration, greening of the desert).

\section{Nexus Opportunities}

The Sahara Forest project integrated production system uses amply available natural resources, namely solar energy and seawater for improving water availability and agricultural/biomass production, that way providing new employment opportunities. Using hydroponic system and the humidity in the air, water needs for food production are 50\% lower compared to other greenhouses.

\section{Technical and Economic Nexus Solutions}

Several major technologies are combined in the Sahara Forest Project $^{3}$, namely electricity production through the use of solar power (PV or CSP), freshwater production through seawater desalination using renewable energy, seawater-cooled greenhouses for food production, and outdoor revegetation using run-off from the greenhouses.

\section{Stakeholders Involved}

The key stakeholders which benefit from such an integrated production system are from the water sector which urgently requires an augmentation of irrigation (and other) water, as well as from the agricultural sector, which relies on the additional desalinated water to maintain and increase agricultural production. The project also involves public and private sector partners from Jordan and abroad, with little engagement of the civil society so far.

\section{Framework Conditions}

The Sahara Forest Project has been implemented at pilot scale so far, including the first pilot with one hectare and one greenhouse pilot in Qatar and a larger "launch station" with three hectares and two greenhouses in Jordan). These pilots have been funded by international organizations such as the Norwegian Ministry of Climate and Environment, Norwegian Ministry of Foreign Affairs and the European Union. Alignment with national policies, institutions and funding as well as upscaling of the project is underway or planned.

\section{Monitoring and Evaluation and Next Steps}

The multi-sectoral planning and investments that are needed to up-scale the project require cooperation among the water, agriculture, and energy sectors and an active involvement of local actors, private companies, and investors. These cooperation and involvement mechanisms are currently being established in Jordan. Given the emphasis on the economic value of the project, public-private partnerships are considered as the appropriate business and governance model, when the project is up-scaled. Scenarios for upscaling (seawater use primarily in low lying areas close to the sea, to avoid energy-intensive pumping) include 50 MW of CSP, 50 hectares of greenhouses, which would produce 34,000 tons of vegetables annually, employ over 800 people, and sequester more than 8,000 tons of $\mathrm{CO}_{2}$ annually.

\footnotetext{
${ }^{3}$ https://www.saharaforestproject.com
} 


\section{Case Study 4: Lajoun Integrated Ecology Centered Development Area, at Municipal Level, Karak Governerate, Jordan (MINARET Project) \\ Nexus Framing}

Increasing water scarcity and water quality degradation and high energy costs (imports of fossil energy) constrain agriculture, contributing to high food import dependence. Nonconventional water solutions (desalination, wastewater reuse, water transfers) make the sector more energy and greenhouse gas intensive.

\section{Nexus Opportunities}

Renewables provide cheaper and climate-smart energy. Recycling across sectors can reduce pressure on natural resources and mitigate water scarcity, recycling of nutrients also saves energy (less energy-intensive industrial fertilizer required). Integrated land use systems and greening of municipal areas can make land more productive, reverse land degradation, restore ecosystems, and improve live quality. Water-, energy-, and climate-smart municipalities can increase their overall resource productivity, generate additional employment, promote economic development, and enhance human well-being.

\section{Technical and Economic Nexus Solutions}

Wastewater is treated and recycled for irrigating crops, for nursery plants and for trees (including constructed wetlands and reed vegetation in wadi); crops are also used as livestock fodder, recycling of agricultural/plant residues/nutrients e.g., through a composting facility improves biomass production; a $3 \mathrm{MW}$ solar power plant provides local energy (e.g., for nurseries) and feeds excess energy into the public grid (legislation has been adjusted e.g., in terms of feed in tariffs-currently $0.25 \$ / \mathrm{kWh}$ ); land rehabilitation through ecosystem-based solutions, e.g., greening along roads, in parks and in the wadi (also for recreation) with plants from the local nursery, improves overall land productivity; native plants are recultivated for fodder, aromatic, medicinal and ornamental purposes (including seedbanks), reed grown in the wadi is used as construction material in the village.

\section{Stakeholders Involved}

Karak municipality is an independent institution which cooperates with many partners in this project, e.g., local families and communities for which the project provides additional jobs. Farmers bring their residues and receive compost and use the treated wastewater. Public institutions include the local, governorate level, and national administration, which coordinate and collaborate across sectors and scales, e.g., for all needed approvals from authorities and ministries, e.g., Ministries of Planning, Municipal Affairs, Water, Energy, and Agriculture (approved composting facility) and Energy. Other partners include Royal Scientific Society (performs studies to determine most suitable native plant species), universities (e.g., Mutah University which also performs studies in the project) and funders. The integrated approaches and experience gained support sustainability transitions beyond the municipality, e.g., strategic planning of national ministries. The private sector is involved e.g., through contracts for wastewater reuse which the project signed with the neighboring industrial complex, as well as a joint solar project with the electricity company. Products from Lajoun are economically competitive in the local context and for local partners.

\section{Framework Conditions}

Policies and legislation in Jordan, e.g., the sustainable energy and climate action plan (SECAP), encourage private sector involvements and investments in technologies such as photovoltaics at all levels. Private investment has been attracted e.g., through DBOT (design, build, operate, transfer) schemes. Local communities, NGOs or CPOs assist the municipality to develop and fund additional activities and promote recycling and the use of local products. The Karak municipality is also member of the Covenant of Mayors for energy and climate which promotes energy efficiency measures and indirectly also integrated/nexus solutions. Stakeholders are engaged from planning through implementation all the way to monitoring and evaluation.

\section{Monitoring and Evaluation and Next Steps}

Cooperation has been established with local societies/communities and universities (Mutah University) and other institutions. Learning, transfer and upscaling are promoted through workshops, meetings, agreements etc., raising awareness about environmental protection and sustainable use of natural resources. The project also improves technical capacities within the municipality's own administration for the management of natural resources.

\section{Case Study 5: Arc en Ciel, Taanayel Farm in the Bekaa Valley, Lebanon} Nexus Framing

Water and energy scarcity/costs constrain agricultural production; poor water, and energy infrastructure and low use efficiencies mutually affect all three sectors (water, energy, agriculture); urban sprawl competes with agriculture for water and land (and energy); the driving forces are bottom up related to the needs and challenges that operating and managing a farm in the Bekaa Valley entails with regards to all the elements of water, energy, land and food and their interlinkages.

\section{Nexus Opportunities}

Water storage and treatment using renewable energy, recycling of wastewater (treatment and reuse) and agricultural residues in multi-functional systems can increase resource use efficiencies and reduce pressure on water, land and energy, reducing pollution of surface, and ground water bodies while increasing agricultural production efficiency. Diversification of products and services (different crops, viniculture, and ecotourism) can increase resilience to climate and other shocks. Opportunities arise from integrating climate change adaptation (e.g., increasing water availability through wastewater recycling) and mitigation (employing water-smart renewable energy). 


\section{Technical and Economic Nexus Solutions}

Solutions include irrigation with reclaimed wastewater, sludge reuse as soil amendment, use of agricultural byproducts for energy (heating and cooking), economic savings from renewables (solar and wind) which are now becoming cheaper than electricity from fossil energy, use of photovoltaics for electricity for water pumping in irrigation and for cooling of agricultural products, enhanced water storage to buffer climate extremes and avoid agricultural losses, and implementation of smart irrigation systems to improve efficiency.

\section{Stakeholders Involved}

Civil society is represented most directly by the NGO managing the farm. The Catholic Church is renting out the farm to the NGO. The local community and some local farmers are employed. More broadly neighboring farmers, municipalities, and unions of municipalities, cooperatives or other user groups could become stakeholders when adopting some of the interventions and the new farm model. Public institutions that could eventually benefit include e.g., local authorities, regional authorities such as the Litani River Authority or the Bekaa Water Establishment (who are the main public institutions concerned with water service provision and management) and national authorities or ministries, e.g., Ministries of Energy and Water, Agriculture, and Environment. Also public and private research institutes (e.g., Lebanese Agricultural Research Institute) could learn from this project. Key private actors are winemaking companies which purchase their grapes from the farm. Other winemakers in the region can benefit from the model practices of this project.

\section{Framework Conditions}

The farm model described in this case study can be managed by NGOs, unions, cooperatives, or other user groups who jointly invest in various activities, e.g., in wastewater treatment, water storage, renewable energy, or composting. This approach could be replicated rather than upscaled, requiring knowledge transfer for deployment of new and adapted technologies. Arc en Ciel could serve as a demonstration farm to gain acceptance of farmers as they can see the concrete benefits themselves and moreover this project could also inform nexus policy making, in particular highlighting the obstacles presented by existing policies, e.g., the current law organizing the electricity sector in Lebanon including metering and the absence of feed-in tariff which does not allow the sale of electricity into the grid; also national standards for re-use of treated wastewater are still missing. Institutional and financial support can potentially come from loan schemes for implementing photovoltaics or more efficient irrigation systems, these investments may come from multiple (international) sources over time. The Arc en Ciel farm puts together piecemeal the various nexus components through donor funding; however, farms in Lebanon are typically small holdings and would have difficulty in securing funding for similar projects. The case opens the door for the small farms to pursue such an integrated and "nexused" development in a collective manner by collaborating through existing cooperatives to secure the funds needed for such a development. An added benefit to this approach is that it would revitalize the cooperatives and better engage local communities.

\section{Monitoring and Evaluation and Next Steps}

The development of a new national agricultural strategy and the current on-going review of the water strategy present opportunities to mainstream elements of a WEF nexus approach in consultation and coordination with other concerned stakeholders from different sectors such as the Ministry of Agriculture, the Ministry of Energy and Water and the Ministry of Economy and Trade. Another opportunity for more integrated management and governance is in the development of national standards for the re-use of treated wastewater in agriculture as an alternative source of water. The government targets for renewable energy and the drive to consistently improve the existing laws due to the renewed interest by the current government could be another entry point. Intended revisions of Law 221 (by which the water sector is governed) as required by the newly passed Water Code present an opening for local water users associations to be set up and for farmers to coordinate activities and even embark on nexus activities on their properties. Furthermore, the intended revisions to Law 221 would enable municipalities to resume their role in water management, a role which the original version of the law had taken away. Such a resumption would enable local authorities, long shunned from action, to be involved in the fields of energy, water and agriculture-three fields in which they have always assumed an indirect role.

\section{COMPARATIVE ANALYSIS ACROSS CASE STUDIES AND LESSONS LEARNED}

All cross-sectoral case studies presented above address the growing problems of resource scarcity and competing resource use both at local and national level. In the context of the extreme water scarcity in the MENA region (Hoff et al., 2017; Waha et al., 2017; FAO, 2019), it is not surprising that water features centrally across all case studies, in terms of the need for increasing water availability, reducing demand, or increasing water use efficiency, e.g., by desalinating water (case study 3 ), recycling of wastewater (case studies 4 and 5) or introducing drip irrigation (case study 1) and reducing costs for pumping (case study 2), with knock-on effects on energy use, agricultural production and farm income. Incidentally this water-centricity mirrors the bias toward the water sector which the water-energy-food nexus has had from the beginning (Hoff, 2011).

The cases in Jordan and Lebanon (case studies 3, 4, and 5) are further tackling scarcity of arable land, by reducing land degradation, increasing land productivity and rehabilitating ecosystems. Their ecosystem-based solutions are in fact closely aligned with the nexus approach. All case studies strongly invest in renewable (in particular solar) energy, reflecting the key trend of energy transitions toward renewables in the MENA region (Hoff et al., 2017), thus reducing fossil fuel dependency and cutting GHG emissions. The case studies thus highlight solutions at the interface of water, land and agriculture, mostly also closely linked to the energy sector. 


\section{Link to SDGs and NDCs}

None of the case studies presented here explicitly aims at SDGs or NDC implementation. However, all of them provide nexus solutions, which-if upscaled-can facilitate integrated SDG and/or NDC implementation. We demonstrate potential outcomes of these interventions in terms of relevant SDGs and other sustainability targets (Figures 1, 2). This information derived from the case studies can support national integration activities such as the planned SDG dashboard by the Jordanian Ministry of Planning (Nassar, 2017).

Building on Weitz et al. (2017b) and their cross-impact matrix for analyzing the interactions between SDG targets, we use a seven-point scale, ranging from high $(+3)$, moderate $(+2)$, and low synergies $(+1)$ to low $(-1)$, moderate $(-2)$ and high tradeoffs $(-3)$ between interventions and SDG targets (see Figure 1), and between case studies and SDG targets (see Figure 2), respectively.

The scores of the interlinkages were based on expert judgement by those co-authors who are most familiar with the respective case study and literature review. The initial scores were reviewed by all other co-authors. Those scores which are not straightforward are referenced with an explanatory note. We acknowledge that the scoring process remains qualitative and judgement-based but argue that it gives a good impression on synergies and tradeoffs that need to be explored further. In sub-sequent research the scoring can be made more robust and inclusive of a differentiation of magnitude vs. likelihood, so it can be used directly by policy makers.

Figure 1 shows the effects of different interventions on selected SDGs and other sustainability targets-from drip irrigation, renewable energy for water pumping and desalination, to reuse of wastewater and agricultural waste products and ecosystem rehabilitation. Several of these interventions are applied in more than one case study.

Figure 2 summarizes synergies and tradeoffs for all case studies in terms of relevant SDG targets. The more positive (further away from the center), the stronger the synergies with the respective SDG targets (negative values indicate tradeoffs or negative impacts). The larger the total area encompassed by the respective colored line, the more positive outcomes the case study enables. The graph thus shows the different foci of each case study. For instance, all five cases are considered to have a positive impact on food security. Case studies 4 and 5 additionally improve water quality and resource use efficiency. The graph further shows where negative impacts may occur (where the colored lines of the case studies enter the inner red area of the graph), calling for measures and institutions to turn tradeoffs into synergies. For example, drip irrigation (case study 1) can improve water use efficiency, but in the absence of effective policies and regulations may not improve water availability, instead leading to increased overall water stress. Similarly this also applies to solar powered irrigation (case study 2) which may lead to over-extraction and depletion of ground water, unless preventive measures are taken. These cases thus support the analysis of tradeoffs between SDGs and the need for incorporating sustainable livelihood perspectives into nexus approaches.
By plotting the potential synergies and tradeoffs of individual interventions and case studies against the different SDG targets (and other sustainability targets), we demonstrate the need for context-specific integrated planning across sectors. While comprehensive quantifications of nexus synergies are still missing (Liu et al., 2018), such qualitative scoring substantiates the role of nexus approaches in the integrated implementation of the 2030 Agenda (Bird et al., 2014; Weitz et al., 2014b; Yumkellaa and Yilliaab, 2015; Rasul, 2016; FAO, 2018; Hoff, 2018). Similarly could the nexus analysis presented in the five case studies facilitate the integrated implementation of the NDCs.

Mitigation targets may for example be addressed through solar powered irrigation systems (case study 2) and through the enhancement of rangelands (case studies 3, 4, and 5), while at the same time these interventions can also contribute to national adaptation goals. Another example for a nexus approach to NDC implementation through integrated adaptation and mitigation is the use of solar power for cooling greenhouses and desalinating seawater (case study 3 ), which reduces the reliance on fossil-fuels and at the same time increases water availability.

\section{Horizontally and Vertically Coordinated Stakeholder Involvement}

In all presented case studies, we find a broad range of stakeholders from different sectors involved-from civil society, to public institutions and private companies. However, institutions from the energy sector seem to be under-represented in most cases. We argue that they should be strongly engaged, given the sector's large investments and ambitious renewables targets in all Arab countries (Hoff et al., 2017), and the close interlinkages with other sectors.

The case studies and their sometimes limited level of integration to date, provide valuable lessons learned for stakeholders across different sectors and levels, for planning, policy making, and implementation.

For example, drip irrigation and solar pumping (case studies 1 and 2) with their unintended rebound effects in terms of overall water use (see Figure 2 and also IRENA, 2016; Font Vivanco et al., 2018; Wong, 2019) emphasize the urgent need to involve stakeholders across different sectors and scales, addressing the "horizontal and vertical nexus" (Hoff, 2018). However, there is only limited evidence of this happening.

The need for cross-sectoral and cross-scale coordination applies similarly to the threat of land degradation in response to practices narrowly defined by e.g., the water sector alone, such as irrigation of marginal land, which in combination with other inputs such as fertilizer can cause salinization and other non-sustainable side effects (Figure 2, case studies 1 and 2, see also Rasul, 2016).

The fact that the Sahara Forest Project (case study 3), which is featured by many publications, depends on international donor funding, is an indication for the difficulty of anchoring (and funding) cross-sectoral projects in a strongly sectoral institutional landscape. The way forward consists of (i) bridging institutions and (ii) better interlinkages between existing institutions (Mansour et al., 2017). Examples of such bridging 


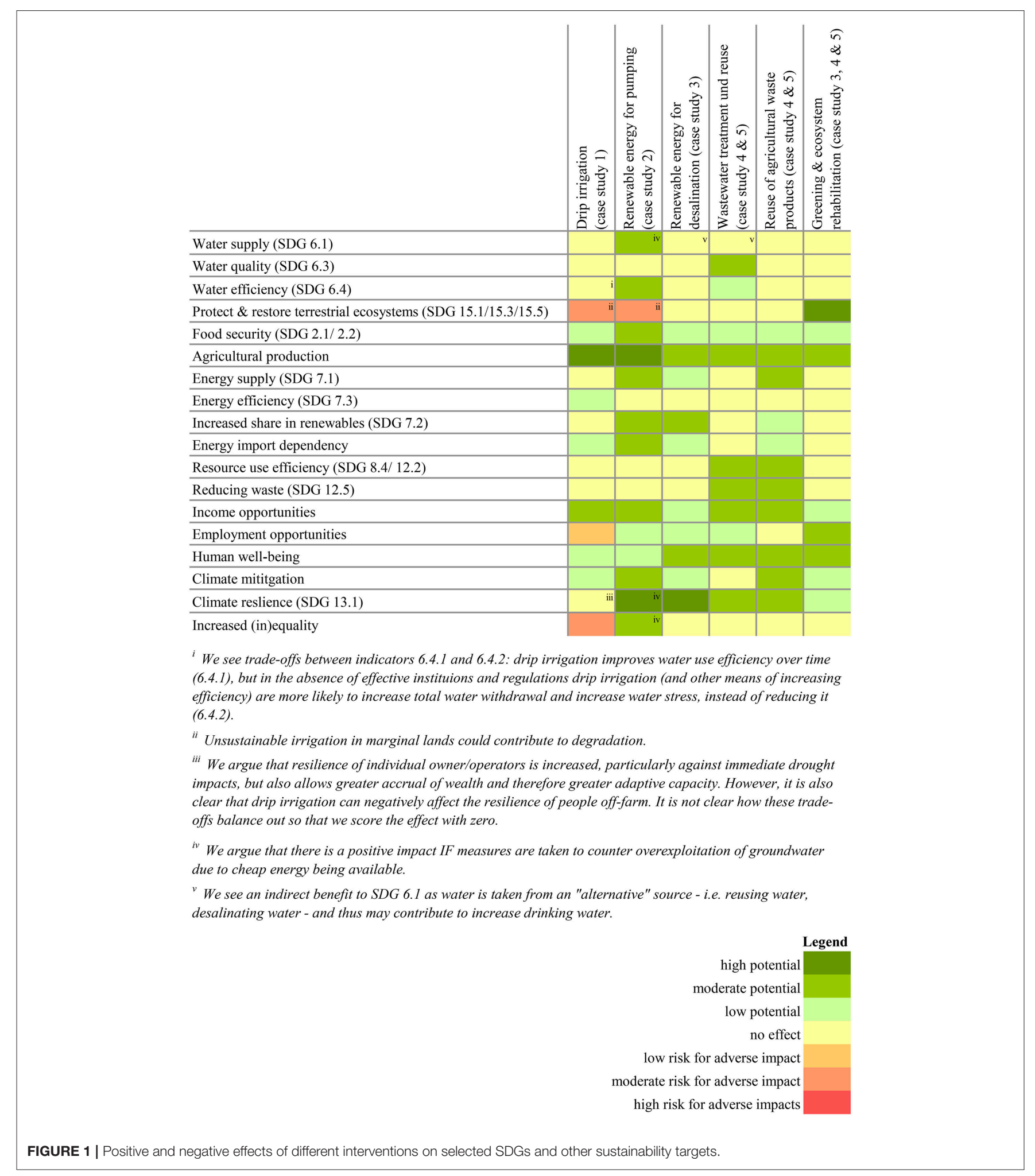

institutions are the Karak municipality (case study 4) which coordinates across sectors and scales and the Litani River Authority, with case study 5 being located in their area of responsibility.
Eventually the engagement of stakeholders engaged at different levels, in different sectors and with different sustainability goals (see Link to SDGs and NDCs) holds chances in two directions: on the one hand it may enhance horizontal 


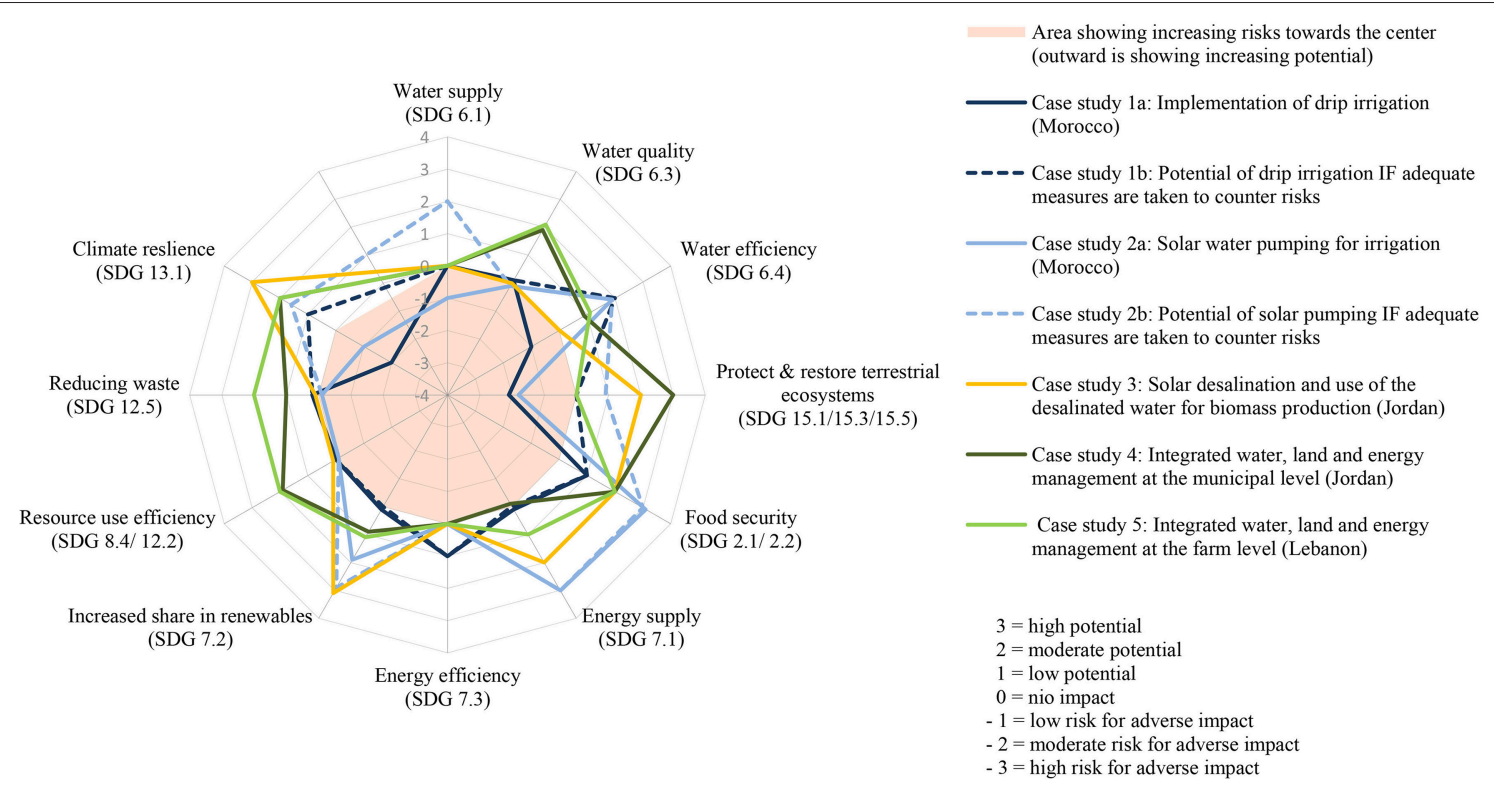

FIGURE 2 | Synergies and tradeoffs for the case studies in terms of relevant SDG targets.

and vertical feedback loops for better informed policy making, and on the other hand it may unleash unconventional funding mechanisms for nexus solutions.

\section{Good Governance and Law Enforcement}

The case studies presented above highlight the need to go beyond a technological focus of nexus implementations and provide complementary policies and regulations. These also need to factor in institutional and socio-economic, in particular poverty reduction objectives and aspects of accessibility of technologies for small-scale farmers (integrated SDG implementation which simultaneously addresses environment and development targets). Biggs et al. (2015) argue in this line, that livelihood perspectives should be an integral part of any planning and implementation of nexus approaches. For example introducing drip irrigation schemes (case study 1) was shown to potentially result in increased social inequity in rural areas (Jobbins et al., 2015). Aligning strategies and action plans across sectors-as promoted by the nexus approach-can also support rural development objectives, by pro-actively addressing potential adverse effects on poverty or inequity. The Karak municipality (case study 4) demonstrates the socio-economic benefits for the local population and businesses of an integrated approach. In Morocco the government plans subsidy schemes for solar powered irrigation systems, which take into account farm size, beneficiaries and other socio-economic criteria for eligibility of these subsidies. The development of this targeted subsidy scheme is informed by the results of case study 2 .

Case study 1 also shows that new technologies can only be successfully introduced and their potential side-effects (here: rebound effects) can only be controlled in an effective policy and regulatory environment. Water security and poverty alleviation depend on enforcement and compliance of cross-sectoral and multi-level governance measures which may be difficult to implement in the rural context of case study 1 in which currently hundreds of legal and illegal wells are active and where sometimes water use is regulated by customary laws. If basic elements of a sustainability transition are lacking, such as feed-in tariffs for decentrally produced electricity, as in Lebanon (case study 4), nexus approaches are bound to fail.

Case study 2 (solar pumping for irrigation) also shows the need for aligning technological, regulative and governmental considerations, emphasizing the need for integrated adaptive planning, policy making and implementation. Stakeholders engaged in case study 2 identified the following requirements: firstly the proper dimensions of the technology (systems design) must be determined in line with the safe yield of the aquifer, this needs to be verified by independent governmental bodies, and these technologies need to be implemented by authorized suppliers providing good quality equipment with traceability and maintenance service. Secondly, the conditionalities of subsidies must be carefully designed (and if needed adapted over time) and recipients have to be trained for the new technology. Governance should-by way of management contracts between farmers and government-specify e.g., the volume of water per farmer and the area of irrigated land, prohibit intercropping, and prescribe remote monitoring of pumps or water flow meters.

\section{The Need for and Challenges of Monitoring Systems}

Good governance and law enforcement require monitoring (including the metering of water use). However, in most of the presented case studies there is little evidence of a monitoring and learning system in place. This means important experience and knowledge on nexus opportunities, but also on potential 
negative impacts and risks may get lost. We further did not find evidence of feedback loops between local on-the-groundexperience and the respective policies and funding schemes. In case study 1 (drip irrigation), monitoring of success is limited to the local level but does not address the overall outcomes at national level. One positive exception in terms of monitoring and evaluation is the case of solar pumping for irrigation in Morocco (case study 2), where multi-loop social learning is practiced, and local experience is used to inform decision makers when tailoring the planned solar irrigation subsidy.

In general, monitoring may be challenged by specific local contexts, e.g., in terms of hydrology, water resources, agriculture, and value chains, which need to be fully understood before the impacts of new technologies, interventions, and projects can be evaluated ex ante. Particularly important in the MENA context is a monitoring of water-related impacts and outcomes at the basin level and the use of that knowledge for adaptive management and policy making. While monitoring of the impacts of wastewater reuse (as in case studies 4 and 5) generally provides a clear picture of positive impacts across sectors and scales, specific challenges exist with regards to effective monitoring and regulation of abstractions related to solar pumping (case study 2). Smart meters might be one option, but many of the wells are illegal and fitting such smart meters would be politically and practically difficult.

However, the initial monitoring and evaluation in some of the case studies, already indicates the potential for synergies across sectors and resources, and the potential contribution of integrated approaches to local, national and regional sustainability goals (see Figures 1, 2). This initial evidence from the case studies underlines the importance of systems for monitoring and evaluation (see also Bhaduri et al., 2015) and institutionalized feedback loops. Nair and Howlett (2014) further highlight monitoring and evaluation as key factors for enabling transfer and up-scaling. As the local effects, e.g., benefits for farmers, may differ from societal, or environmental effects at large (e.g., reduction of GHG emission or of import dependence for fossil fuels), monitoring systems need to address all levels and scales (from local to national and regional) into account to inform coherent policy making across levels and scales.

\section{Bottom Up vs. Top Down Approaches, and the Potential for Transfer and Upscaling}

Most of the presented case studies take a bottom-up approach, which starts from small-scale solutions (e.g., solar irrigation and drip irrigation in case studies 1 and 2). These solutions operate at the scale of individual farms or communities (e.g., wastewater recycling and biomass production in case studies 3, 4, and 5) and through private public partnerships (e.g., desalination and land rehabilitation in case studies 3, 4, and 5). However, while in principle these bottom up cases have high potential for transfer and up-scaling, only one-case study 2: solar powered irrigation-has already gone to larger scale.

Besides strong political support and synergies with ongoing policies/programmes and adequate monitoring (Nair and
Howlett, 2014), transfer and upscaling depends on the capability of farmers or communities to invest. Moreover, farmersin particular small farmers-experience administrative barriers (e.g., farmers don't have permits to dig wells), institutional barriers (e.g., farmers don't have private land tenure, etc.), or technical barriers (e.g., farms are too small to make investment profitable). Westermann et al. (2018) further point out in their review of eleven case studies, that addressing equity issues and integrating knowledge across multiple levels are additional challenges in scaling up.

A combination of public money (subsidies, interest-free credit) and/or private investment can promote new technologies and integrated approaches, as can small farmers cooperating to adopt shared integrated systems. Up-scaling depends further on knowledge transfer and skills development (FAO, 2018). Stakeholders involved in case study 2 noted that economic viability can have a remarkable impact on knowledge transfer and uptake: pioneer farmers financed and successfully operated solar irrigation systems on their own. Their experiences and demonstrations created a demand by other farmers. This cumulated demand called for action by the government to support the investment into solar powered irrigation, including targeted subsidies. Seeing a system working on neighboring farms thus remains very convincing, highlighting the need for demo projects, study tours and other forms of knowledge transfer for farmers, extension officers and policy makers. The international network of solar powered irrigation projects also promotes knowledge transfer across countries and regions. The Karak municipality (case study 4) is a good example where these forms of knowledge transfer are facilitated at the local level. Integrated solutions and lessons learned are showcased to farmers, entrepreneurs and policy makers by actively facilitating visits and study tours.

We can also draw important lessons from case study 1 (drip irrigation in Morocco). The Government of Morocco has been encouraging drip irrigation for several decades, with focused investments in specific irrigation schemes as well as general policies subsidizing and incentivizing the adoption of drip irrigation. This has helped to improve the resilience of Morocco's agricultural sector against drought (Sadiki, 2017). However, the top-down approach by the government (to save water and energy) and the bottom up approach by farmers (searching for profit) are not well aligned, and hence farmers don't always use the technology efficiently or in the way anticipated by the policymakers. As a consequence aquifer levels continue to fall in some areas and energy subsidy bills increase.

\section{CONCLUSION}

The nexus approach has the potential to enhance human wellbeing, while reducing pressures on the environment and natural resources ("decoupling"), through integrated management and governance and consequently improved resource use efficiency. Such an approach is urgently needed, given the enormous pressures the MENA region is faced with. However, as we show in this paper, technological improvements need to be embedded 
in appropriate framework conditions, including appropriate policies, regulation, and monitoring mechanisms. Only then can the benefits of the nexus approach materialize, without causing negative environmental or socio-economic side effects in other sectors or at other scales. Also there is a need for capacity building and sharing of experience from initial implementations with a wide range of actors from different sectors and scales. The case studies presented and synthesized here provide for the first time consolidated evidence for the MENA region from a set of integrated projects and implementations on the ground. While there is no quantification of the benefits and added value of a nexus approach yet, the evidence from the case studies can already be used by policy makers for better coordination across sectors and improvements in terms of horizontal and vertical policy coherence. Such changes toward more integrated governance can incentivize further nexus implementations and

\section{REFERENCES}

Al-Bakri, J. T., Salahat, M., Suleiman, A., Suifan, M., Hamdan, M. R., Khresat, S., et al. (2013). Impact of Climate and Land use Changes on Water and Food Security in Jordan: Implications for Transcending "the Tragedy of the Commons". Jordan Ministry of Water and Irrigation, Water Reallocation Policy. Available online at: www.mwi.gov.jo/sites/en-us/Hot\%20Issues/Strategic\%20Documents $\% 20$ of $\% 20 \% 20$ The $\% 20$ Water\%20Sector/Water\%20Reallocation\%20Policy \%2025.2.2016.pdf (accessed October 31, 2018).

Albrecht, T. R., Crootof, A., and Scott, C. A. (2018). The water-energy-food nexus. A systematic review of methods for nexus assessment. Environ. Res. Lett. 13. doi: 10.1088/1748-9326/aaa9c6

Allan, T., Keulertz, M., and Woertz, E. (2015). The water-food-energy nexus: an introduction to nexus concepts and some conceptual and operational problems. Int. J. Water Res. Dev. 31, 301-311. doi: 10.1080/07900627.2015.1029118

Al-Saidi, M., and Elagib, N. A. (2017). Towards understanding the integrative approach of the water, energy and food nexus. Sci. Total Environ. 574, 1131-1139. doi: 10.1016/j.scitotenv.2016.09.046

Bazilian, M., Rogner, H., Howells, M., Hermann, S., Arent, D., Gielen, D., et al. (2011). Considering the energy, water and food nexus. Towards an integrated modelling approach. Energy Policy 39, 7896-7906. doi: 10.1016/j.enpol.2011.09.039

Bhaduri, A., Ringler, C., Dombrowski, I., Mohtar, R., and Scheumann, W. (2015). Sustainability in the water-energy-food nexus. Water Int. 40, 723-732. doi: 10.1080/02508060.2015.1096110

Biggs, E. M., Bruce, E., Boruff, B., Duncan, J. M. A., Horsley, J., Pauli, N., et al. (2015). Sustainable development and the water-energy-food nexus: a perspective on livelihoods. Environ. Sci. Policy 54, 389-397. doi: 10.1016/j.envsci.2015.08.002

Bird, J., Dodds, F., McCornick, P. G., and Shah, T. (2014). Water-Food-Energy Nexus. Water for Food Faculty Publications 4. Available online at: http:// digitalcommons.unl.edu/wffdocs/4

Bizikova, L., Roy, D., Swanson, D., Venema, H. D., and McCandless, M. (2013). The Water-Energy-Food Security Nexus: Towards a Practical Planning and DecisionSupport Framework for Landscape Investment and Risk Management, IISD.

Brandi, C., Dzebo, A., Janetschek, H., Lambert, C., and Savvidou, G. (2017). NDC-SDG Connections. German Development Institute, Stockholm Environment Institute.

Endo, A., Tsurita, I., Burnett, K., and Orencio, P. M. (2017). A review of the current state of research on the water, energy, and food nexus. J. Hydrol. 11, 20-30. doi: 10.1016/j.ejrh.2015.11.010.

FAO (2015). Regional Overview of Food Insecurity, Near East and North Africa, Cairo, Egypt.

FAO (2018). Policy Brief \#9: Water-Energy-Food Nexus for the Review of $S D G$ 7. Support SDG7 review at the UN High-Level Political Forum in investments and upscaling of solutions beyond pilot scale, which in turn would further strengthen the nexus evidence and knowledge base. Continued dialogue and feedback loops between implementers of the nexus approach on the ground, policy makers, and the general public are the way forward to make the nexus a key approach for contributing to the integrated implementation of the SDGs and other sustainability goals. We recommend to further populate the basic framework developed here with additional evidence from more case studies within and beyond the MENA region, in order to develop a solid and generalizable evidence base for successful nexus implementation.

\section{AUTHOR CONTRIBUTIONS}

All authors listed have made a substantial, direct and intellectual contribution to the work, and approved it for publication.
July 2018. Available online at: https://sustainabledevelopment.un.org/content/ documents/17483PB_9_Draft.pdf

FAO (2019). FAO Aquastat - Online Database. Available online at: http://www.fao. org/nr/water/aquastat/main/index.stm, (last accessed 31 January 2019).

Flammini, A., Puri, M., Pluschke, L., and Dubois, O. (2014). Walking the Nexus Talk, Assessing the Water-Energy-Food Nexus. FAO Environment and Natural Resources management Working paper \#58. Available online at: http://www.fao. org/3/ai3959e.pdf

Font Vivanco, D., Sala, S., and McDowall, W. (2018). Roadmap to rebound: how to adress rebound effects from resource efficiency policy. Sustainability 10:2009. doi: $10.3390 /$ su10062009

GWP (2000). Integrated Water Resources Management, Global Water Partnership. TAC Background Paper, p. 4.

Hagemann, N., and Kirschke, S. (2017). Key issues of interdisciplinary NEXUS governance analyses. Lessons learned from research on integrated water resources management. Resources 6:9. doi: 10.3390/resources6010009

Hoff, H. (2011). "Understanding the Nexus," in Background Paper for the Bonn2011 Conference: The Water, Energy and Food Security Nexus. Stockholm: Stockholm Environment Institute, Stockholm.

Hoff, H. (2018). "Integrated SDG Implementation - How a Cross-Scale (Vertical) and Cross-Regional Nexus Approach Can Complement CrossSectoral (Horizontal) Integration," in Managing Water, Soil and Waste Resources to Achieve Sustainable Development Goals, eds S. Hülsmann and R. Ardakanian (Cham: Springer). 149-163. doi: 10.1007/978-3-319-75163-4_7

Hoff, H., Al-Zubari, W., Mansour, L., Abaza, H., Biad, M., Al Ouran, N., et al. (2017). Mainstreaming the Water-Energy-Food Security Nexus into Policies and Institutions in the MENA Region: Nexus Evidence Base. A study implemented by GFA Consulting Group, Stockholm Environment Institute and Adelphi on behalf of GIZ.

IRENA (2016). Solar Pumping for Irrigation: Improving Livelihoods and Sustainability. The International Renewable Energy Agency, Abu Dhabi.

Jobbins, G., Kalpakian, J., Chriyaa, A., Legrouri, A., and El Mzouri, E. H. (2015). To what end? Drip irrigation and the water-energy-food nexus in Morocco. Int. J. Water Resour. Dev. 31, 393-406. doi: 10.1080/07900627.2015.1020146

Lafferty, W. M., and Hovden, E. (2002). Environmental Policy Integration. Towards an Analytical Framework. Centre for Development and the Environment, University of Oslo. Oslo (7/02). Available online at: http://www.prosus.org/ prosusFTP/prosusrep/publications/prosusrep2002_07.pdf (accessed October 01, 2018).

Leck, H., Conway, D., Bradshaw, M., and Rees, J. (2015). Tracing the water-energyfood nexus: description, theory and practice. Geogr. Compass 9, 445-460. doi: 10.1111 /gec3.12222

Liu, J., Hull, V., Godfray, H. C. J., Tilman, D., Gleick, P., Hoff, H., et al. (2018). Nexus approaches to global sustainable development. Nat. Sustain. 1, 466-476. doi: $10.1038 / \mathrm{s} 41893-018-0135-8$ 
Liu, J., Yang, H., Cudennec, C., Gain, A. K., Hoff, H., Lawford, R., et al. (2017). Challenges in operationalizing the water-energy-food nexus. Hydrol. Sci. J. 62, 1714-1720. doi: 10.1080/02626667.2017.1353695

Mansour, L., Kramer, A., Abaza, H., Al Ouran, N., Al-Zubari, W., Carius, A., et al. (2017). Mainstreaming the Water-Energy-Food Security Nexus into Policies and Institutions in the MENA Region: National Guidelines on Mainstreaming the Waterenergy-Food (WEF) Security Nexus into Policies and Institutions in Egypt and Jordan. GIZ Report.

Mohtar, R., and Daher, B. (2016). Water-energy-food nexus framework for facilitating multi-stakeholder dialogue,Water Int. 41, 655-661. doi: 10.1080/ 02508060.2016.1149759

Mohtar, R. H., and Daher, B. (2012). "Water, Energy, and Food: The Ultimate Nexus," in Encyclopedia of Agricultural, Food, and Biological Engineering, 2nd Edn (Abingdon: Taylor \& Francis), 1-15. doi: 10.1081/E-EAFE2-120048376

Nair, S., and Howlett, M. (2014). Design and Scaling Up of Policy Experiments and Pilot Lessons for the Water Sector. Lee Kuan Yew School of Public Policy Research Paper, p. 14-35.

Nassar, L. (2017). A Guidance note for SDG Implementation in Jordan: Water, Energy, and Climate Change. WANA Institute, Amman, Jordan.

OECD/FAO (2018). OECD-FAO Agricultural Outlook 2018-2027. Organization for Economic Cooperation and Development Paris, Food and Agriculture Organization, Rome.

özerol, G., Bressers, H., and Coenen, F. (2012). Irrigated agriculture and environmental sustainability: an alignment perspective. Environ. Sci. Policy 23, 57-67. doi: 10.1016/j.envsci.2012.07.015

Pardoe, J., Conway, D., Namaganda, E., Vincent, K., Dougill, A. J., and Kashaigili, J. J. (2017). Climate change and the water-energy-food nexus: insights from policy and practice in Tanzania. Climate Policy 18, 863-877. doi: 10.1080/14693062.2017.1386082

Rasul, G. (2016). Managing the food, water, and energy nexus for achieving the sustainable development goals in South Asia. Environ. Dev. 18, 14-25. doi: 10.1016/j.envdev.2015.12.001

Rasul, G., and Sharma, B. (2015). The nexus approach to water-energy-food security: an option for adaptation to climate change. Climate Policy 16, 682-702. doi: 10.1080/14693062.2015.1029865

Sadiki, M. (2017). "La Rareté de l'eau: Défis et Opportunités: cas du secteur agricole au MAroc," in Séminaire de haut niveau" Rareté de l'eau: Défis et Opportunités" (Rome).

Scharpf, F. W. (1972) "Komplexität als Schranke der politischen Planung," in Erwin Faul (Hg.): Gesellschaftlicher Wandel und Politische Innovation (Politische Vierteljahresschrift Sonderheft 4/1972), (Wiesbaden: VS Verlag für Sozialwissenschaften), 168-192. doi: 10.1007/978-3-322-88716-0_10

Scott, A. (2017). Making governance work for water-energy-food nexus approaches. Working Paper. London: Climate and Development Knowledge Network (CDKN).

Sullivan, P. (2013). "The Water-Energy-Food Conflict Nexus in MENA," in Presentation at the Annual Conference of the Association of Opinion Journalists (Newport, RI).
Waha, K., Krummenauer, L., Adams, S., Aich, V., Baarsch, F., Coumou, D., et al. (2017). Climate Change Impacts in the Middle East and Northern Africa (MENA) Region and Their Implications for Vulnerable Population Groups. Regional Environmental Change.

Waterbury, J. (2017). "Water and Water Supply in The MENA: Less of the Same," in Water, Energy and Food Sustainability in the Middle East, eds Badran et al. (Springer Verlag), 57-84.

Weitz, N., Carlsen, H., Nilsson, M., and Skånberg, K. (2017b). Towards systemic and contextual priority setting for implementing the 2030 Agenda. Sustain. Sci. 13, 531-548. doi: 10.1007/s11625-017-0470-0

Weitz, N., Huber-Lee, A., Nilsson, M., Davis, M., and Hoff, H. (2014a). CrossSectoral Integration in the Sustainable Development Goals: A Nexus Approach, Stockholm Environment Institute. Discussion Brief.

Weitz, N., Nilsson, M., and Davis, M. (2014b). A nexus approach to the post-2015 agenda: formulating integrated water, energy, and food SDGs. SAIS Rev. Int. Affairs 2, 37-50. doi: 10.1353/sais.2014.0022

Weitz, N., Strambo, C., Kemp-Benedict, E., and Nilsson, M. (2017a). Closing the governance gaps in the water-energy-food nexus. Insights from integrative governance. Glob. Environ. Change 45, 165-173. doi: 10.1016/j.gloenvcha.2017.06.006

Westermann, O., Förch, W., Thornton, P., Körner, J., Cramer, L., and Campbell, B. (2018). Scaling up agricultural interventions: case studies of climate-smart agriculture. Agricul. Syst. 165, 283-293. doi: 10.1016/j.agsy.2018.07.007

White, D. D., Jones, J. L., Maciejewski, R., Aggarwal, R., and Mascaro, G. (2017). Stakeholder analysis for the food-energy-water nexus in phoenix, arizona: implications for Nexus Governance. in Sustainability 9:2204. doi: $10.3390 /$ su9122204

Wong, S. (2019). "Decentralised, Off-Grid Solar Pump Irrigation Systems in Developing Countries-Are They Pro-poor, Pro-environment and Prowomen?", in Climate Change-Resilient Agriculture and Agroforestry, eds P. Castro, A. Azul, W. Leal, U. Filho, and W. Azeiteiro (Cham: Springer), 367-382. doi: 10.1007/978-3-319-75004-0_21

Yumkellaa, K. K., and Yilliaab, P. T. (2015). Framing the water-energy nexus for the post-2015 developmen agenda. Aquatic Procedia 5, 8-12. doi: 10.1016/j.aqpro.2015 10.003

Conflict of Interest Statement: The authors declare that the research was conducted in the absence of any commercial or financial relationships that could be construed as a potential conflict of interest.

Copyright (c) 2019 Hoff, Alrahaife, El Hajj, Lohr, Mengoub, Farajalla, Fritzsche, Jobbins, Özerol, Schultz and Ulrich. This is an open-access article distributed under the terms of the Creative Commons Attribution License (CC BY). The use, distribution or reproduction in other forums is permitted, provided the original author(s) and the copyright owner(s) are credited and that the original publication in this journal is cited, in accordance with accepted academic practice. No use, distribution or reproduction is permitted which does not comply with these terms. 